\title{
Comparative Analyses Concerning Triaxial Compressive Yield Criteria of Coal with the Presence of Pore Water
}

\author{
Rulin Liu $\mathbb{D}^{1,2}$ Yanbin Yu ${ }^{1}{ }^{1,2,3}$ Weimin Cheng, ${ }^{1,3}$ Qingfeng Xu, ${ }^{1,3}$ Haotian Yang, ${ }^{1,3}$ \\ and Jialong Shen ${ }^{1,3}$ \\ ${ }^{1}$ State Key Laboratory of Mining Disaster Prevention and Control Co-founded by Shandong Province and the Ministry of Science \\ and Technology, Shandong University of Science and Technology, Qingdao 266590, China \\ ${ }^{2}$ Shandong Key Laboratory of Civil Engineering Disaster Prevention and Mitigation, Shandong University of Science and Technology, \\ Qingdao, Shandong 266590, China \\ ${ }^{3}$ College of Safety and Environmental Engineering, Shandong University of Science and Technology, Qingdao, \\ Shandong 266590, China \\ Correspondence should be addressed to Yanbin Yu; he_yyb@163.com
}

Received 22 September 2019; Revised 15 November 2019; Accepted 6 January 2020; Published 3 February 2020

Academic Editor: Constantinos Loupasakis

Copyright ( 92020 Rulin Liu et al. This is an open access article distributed under the Creative Commons Attribution License, which permits unrestricted use, distribution, and reproduction in any medium, provided the original work is properly cited.

\begin{abstract}
The least absolute deviation is used as a metric to analyze the applicability of five yield criteria, to describe the yield characteristics of coal based on triaxial compressive strength tests on natural, water-saturated, and seepage coal samples with the presence of pore water. The results show that the strength of coal exhibits nonlinear characteristics with the increase of confining pressure, which the linear Coulomb criterion fails to authentically describe. Although the parabolic Mohr criterion can describe the nonlinearity feature more decently than the linear yield criterion, the fitting error is significant, and the uniaxial compressive strength of coal is overestimated. The Hoek-Brown criterion, quadratic polynomial criterion, and exponential criterion yield decent fitting quality for the coal rock. In particular, the exponential strength criterion can accurately reflect the actual uniaxial compressive strength of the rock. However, the differential principle yield stress for an infinite confining pressure calculated from the exponential strength criterion is lower than the measured value. Furthermore, by employing effective stress principle to analyze the yield criteria for the saturated and seepage coal samples, one can find that the quadratic polynomial criterion and the exponential criterion can also reflect the changes of yield characteristics during the fluid-solid coupling triaxial compression test.
\end{abstract}

\section{Introduction}

In the subsurface mining engineering, hydroelectric power generation, petroleum, and geological engineering applications $[1,2]$, how to calculate and predict the rock strength is of great significance to the researchers, e.g., engineering designers. The accuracy of the calculation here directly dictates the quality and safety of engineering construction, and then affects the safety of workers. However, the rock strength is closely related to the geological environment. The mechanical properties of the rock also differ in response to the change of rock stress and geological environment. The test of rock strength under various stress states has been a hot research topic for scholars. With the advancement of experi- mental techniques for testing rock mechanics, the corresponding rock strength evaluation criteria have also been subject to continuous corrections and improvements.

Since its advent in 1776, the Coulomb yield criterion has become one of the most widely used yield criteria in geotechnical engineering [3]. In 1900, Mohr extended the Coulomb shear strength criterion to account for the three-dimensional stress state, leading to the M-C criterion $[4,5]$. According to the behaviors of fracturing and rock failure and by taking into consideration the triaxial testing data and the rock mass in situ measurement results, Hoek and Brown put forward in 1980 the Hoek-Brown empirical yield criterion [6], which, based on the experimental validation and practical improvements, has been widely accepted by the rock mechanics and 
engineering community. In addition, many scholars have extended the yield criteria based on experimental measurement and theoretical analyses, giving rise to numerous new criteria, e.g., Drucker-Prager failure criterion [7], Griffith criterion and its associated Murrell three-dimensional extension [8], Mogi yield criterion [9], power function-based yield criterion [10-12], exponential yield criterion $[13,14]$, and unified strength theory [15].

With the continuous application and development of yield criterion in engineering practice, scholars have carried out experiments and analyses on the yield criteria under various stress paths based on different rock types, with a plethora of results published. Among them, Zhao [16] establishes a dynamic Mohr-Coulomb criterion and a dynamic Hoek-Brown criterion for a low loading rate through a series of experiments, e.g., uniaxial compression and triaxial compression. Based on the linear Mogi criterion, Al-Ajmi and Zimmerman [17, 18] established the Mogi-Coulomb criterion by analyzing the relationship between the fitting parameters and the antishearing strength parameters based on linear Mogi criterion. Costamagna and Bruhns [19] establish a nonlinear strength criterion with four complex parameters, which can be transformed into multiple variants based on different selections of parameters. You $[20,21]$ thoroughly analyze the stress-strain curves of defective rock samples, based on which the impact of confining pressure on the triaxial strength of rock samples is determined, and the yield criteria associated with various rock types are systematically analyzed. Although significant achievements have been made concerning the yield criteria, these criteria are all subject to certain practical limitations with a lack of universal applicability. Therefore, systematic studies are still required for developing yield criteria under different conditions.

Many engineering practices have indicated that the rock is not only affected by the stress field in the Earth's crust but also affected by the presence of water to certain degrees. In some cases, even high osmotic pressure exists in the rock, leading to a complicated water environment that affects the rock. In order to explore the influence of groundwater on rock strength, Ojo and Brook [22] summarize the relevant research results and conclude that the existence of water tends to weaken rock strength, with the increase of humidity compromising the compressive and tensile strengths of rock. Vásárhelyi and Ván [23, 24] test the uniaxial compressive strength and the modulus of elasticity of dry and saturated limestone and find that the strength and modulus of elasticity are reduced by about $34 \%$ after the saturation of rock with water. Baud et al. [25] systematically analyze the water's rock-weakening effect based on mechanical and chemical mechanisms and find that the water's effect for reducing triaxial compressive strength is attributed to a decrease in the surface energy and the internal friction coefficient of the rock. For the subsurface mining application, Peng et al. [26] study the mechanical properties of deep coal rock samples under five different confining pressure conditions using a triaxial compression test system. Medhurst and Brown [27] conduct a conventional triaxial compression test on a large coal sample using a rock servo tester. The results show that with an increase of confining pressure, the peak strength of the coal sample increases and the expansion deformation decreases. Bell and Jermy [28] analyze the strength and deformation characteristics of coal samples under different stress conditions by performing compressive tensile and permeability tests on coal samples from the East Transvaal coal field. In addition, most of the scholars consider the impact of groundwater environment on the mechanical properties of rocks by conducting related experiments for various rock types. However, the measured results were primarily used to analyze the rock strength and deformation under various stress conditions based on the classical Coulomb yield criterion. In the case of underground mining engineering, due to the joint effects of in situ stress field and seepage field, the coal yield characteristics are more complicated, calling the effectiveness of the classical yield criteria in reflecting the actual rock strength under various stress states into question. Therefore, in-depth investigation in this regard is needed to ensure the reliable safety design of coal mines. To this end, the present paper obtains the conventional triaxial compressive strength of natural and saturated rock as well as the correlation between stress and strain with the presence of pore water seepage under various confining pressures by employing a MTS815 servo controlled rock mechanic testing system. Linear, parabolic and exponential yield criteria are used to characterize the strength of the rock sample subject to various stresses and water environments as well as the applicability of various yield criteria. The results obtained here can serve as a reference for the safety design concerning the operation of underground coal mines.

\section{Triaxial Strength Test and Yield Criterion}

2.1. Triaxial Strength Test of Coal. An MTS815 electrohydraulic servo rock test system was applied to three types of coal samples from the Yanzhou Coal Mining Co. Dongtan coal mine [29, 30]. Triaxial compression tests of natural and saturated coal and a triaxial seepage compression test of saturated coal were carried out. The MTS815 electrohydraulic servo rock test system is equipped with three independent servo systems to control the axial pressure, confining pressure, and pore pressure. Test applies a certain axial compression $\sigma_{1}$, confining pressure $\sigma_{3}$, pore pressure $P_{1}$, and always maintain $P_{1}<\sigma_{3}$; osmotic pressure is produced at the two ends of the test pieces $\left(\triangle P=P_{1}-P_{2}\right)$ by reducing the pore pressure at the end of the specimen to $P_{2}$, so that pore water seepage under the effects of osmotic pressure is through the pore and fracture. When a triaxial seepage compression test of DT coal is carried out, the pore water pressures $P_{1}$ and $P_{2}$ are $3.5 \mathrm{MPa}$ and $2 \mathrm{MPa}$, respectively. The coal sample is fully saturated with water before the seepage test. When a triaxial seepage compression test of $\mathrm{BD}$ and $\mathrm{YH}$ coal is carried out, the pore water pressures $P_{1}$ and $P_{2}$ are $3.8 \mathrm{MPa}$ and $2.3 \mathrm{MPa}$. Prior to testing, we selected coal samples with no obvious cracks. We then used the ultrasonic velocity measurement method to screen the selected coal samples and used those samples which exhibited similar sonic velocities and waveforms for testing. The results of the triaxial strength test and the data utilized for assessing the yield criteria are shown in Table 1. The principle of triaxial tests is shown in Figure 1. 


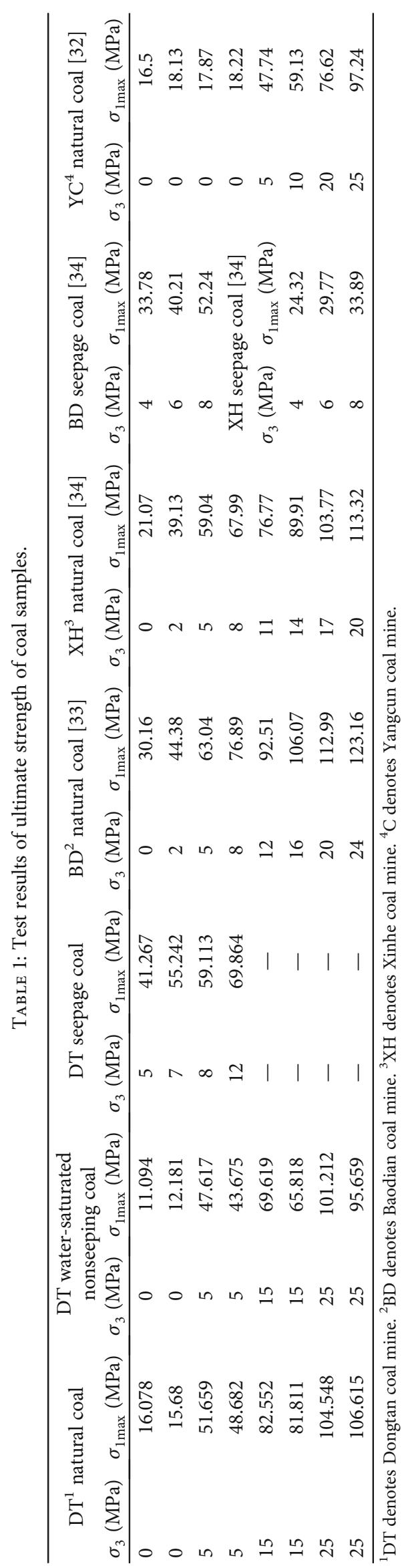




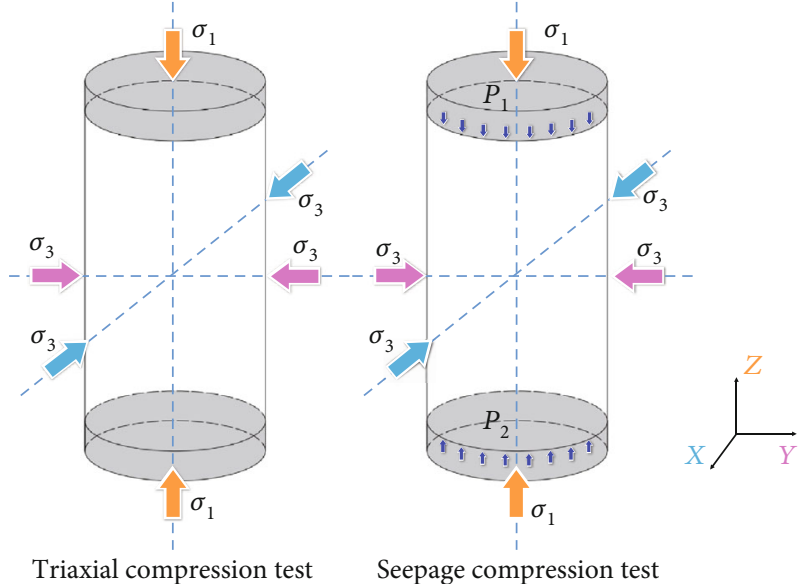

FIgURE 1: Diagram of the tests' principle.

\subsection{Mathematical Expression of Yield Criteria}

2.2.1. Linear Yield Criterion. Coulomb yield criterion is established by assuming that the rock failure is induced by sheer stress, and the maximum shear stress the rock can withstand $\tau_{\max }$ is jointly dictated by the cohesion $c$ and the internal friction [31], i.e.,

$$
\tau_{\max }=c+\mu \sigma
$$

where $\mu$ is the internal friction coefficient; $\sigma$ denotes the normal stress. The equation above can be expressed based on the principle stress as follows:

$$
\sigma_{1 \max }=\frac{2 c \cos \varphi}{1-\sin \varphi}+\frac{1+\sin \varphi}{1-\sin \varphi} \sigma_{3},
$$

where $\sigma_{1 \max }$ denotes the maximum principal stress; $\sigma_{3}$ denotes the minimum principal stress; $\varphi$ denotes the internal friction angle.

2.2.2. Parabolic Yield Criterion. Considering the symmetry, the parabolic Mohr criterion (You 2010) can be written as follows:

$$
\sigma=\frac{\tau_{\max }^{2}}{a T_{0}}-T_{0}
$$

where $T_{0}$ denotes the uniaxial tensile strength of rock, and $a$ denotes the $a$ parameter related to the compressive strength of the rock $R$ :

$$
a=\frac{R^{2}}{(1+\sqrt{1+R})^{2}} .
$$

The corresponding principal stress relationship can be expressed as follows:

$$
\left(\sigma_{1 \max }-\sigma_{3}\right)^{2}=2 a T_{0}\left(\sigma_{1 \max }+\sigma_{3}\right)+4 a T_{0}^{2}-a^{2} T_{0}^{2} .
$$

The equation above can also be expressed as follows:

$$
\left(\sigma_{1 \max }-\sigma_{3}\right)^{2}=A\left(\sigma_{1 \max }+\sigma_{3}\right)+C,
$$

where $A$ and $C$ are unknown parameters, which can be determined based on linear regression to finalize the yield criterion expression. Equation (6) can be equivalently written as follows:

$$
\sigma_{1 \max }=\sigma_{3}+\sigma_{\mathrm{c}}-\sigma_{\mathrm{D}}+\sqrt{4\left(\sigma_{\mathrm{c}}-\sigma_{\mathrm{D}}\right) \sigma_{3}+\sigma_{\mathrm{D}}^{2}}
$$

where $\sigma_{c}$ denotes the uniaxial compressive strength of a complete rock, and $\sigma_{\mathrm{D}}$ denotes an unknown parameter to be determined here.

2.2.3. Hoek-Brown Yield Criterion. Based on the experimental testing of rock strength, Hoek and Brown put forward an empirical yield criterion, whose general form [6] is shown below:

$$
\sigma_{1 \max }=\sigma_{3}+\sigma_{\mathrm{c}}\left(\frac{m \sigma_{3}}{\sigma_{\mathrm{c}}}+s\right)^{n},
$$

where $\sigma_{c}$ denotes the uniaxial compressive strength of a complete rock; $m, s$, and $n$ are constants dictated by the characteristics of the rock. For a typical complete rock, $s=1$ and $n=0.5$.

For a complete rock, Equation (8) can be simplified as follows:

$$
\sigma_{1 \max }=\sigma_{3}+\sigma_{\mathrm{c}}\left(\frac{m \sigma_{3}}{\sigma_{\mathrm{c}}}+1\right)^{0.5}
$$

Equation (9) is also referred to as the special HoekBrown criterion, which can also be rewritten as follows:

$$
\left(\sigma_{1 \max }-\sigma_{3}\right)^{2}=m \sigma_{\mathrm{c}} \sigma_{3}+\sigma_{\mathrm{c}}^{2}
$$

The square of the principal stress deviator is linearly correlated with the minimum principal stress, based on which the parameters $m$ and $\sigma_{c}$ can be determined by applying linear regression to the experimental data.

2.2.4. Quadratic Polynomial Criterion. In order to facilitate the regression of experimental data, one can introduce additional unknown parameters to the criterion formula to modify the existing yield criterion. Also, a multitude of options exist for correcting the yield criterion. The general form of the parabolic yield criterion can be rewritten in a quadratic polynomial form [13]:

$$
\left(\sigma_{1 \max }-\sigma_{3}\right)^{2}=A \sigma_{1 \max }+B \sigma_{3}+C,
$$

where $A, B$, and $C$ are unknown parameters. In the case where $A=B$, the equation above becomes Equation (6), while 


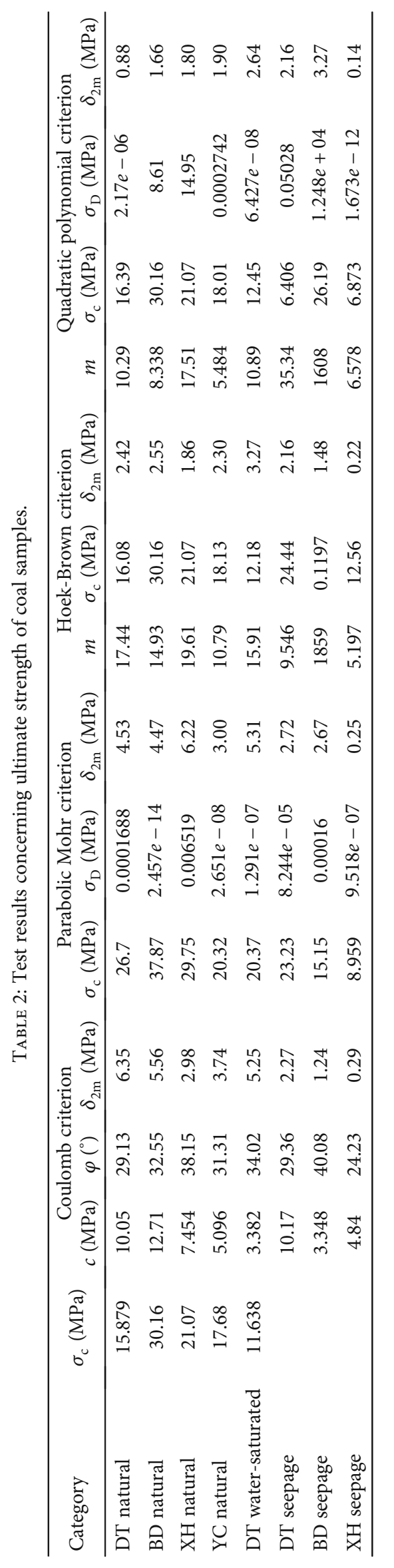


TABLE 3: Fitted results of exponential yield criterion.

\begin{tabular}{|c|c|c|c|c|c|}
\hline \multirow{2}{*}{ Category } & \multirow{2}{*}{$\sigma_{\mathrm{c}}(\mathrm{MPa})$} & \multicolumn{4}{|c|}{ Exponential yield criterion } \\
\hline & & $K_{0}$ & $Q_{0}(\mathrm{MPa})$ & $Q_{\infty}(\mathrm{MPa})$ & $\delta_{2 \mathrm{~m}}(\mathrm{MPa})$ \\
\hline DT natural & 15.879 & 8.059 & 16.08 & 84.83 & 1.41 \\
\hline BD natural & 30.16 & 7.62 & 30.16 & 110.1 & 0.49 \\
\hline $\mathrm{XH}$ natural & 21.07 & 5.876 & 26.72 & 145.9 & 2.40 \\
\hline YC natural & 17.68 & 5.075 & 18.13 & 89.1 & 2.36 \\
\hline DT water-saturated & 11.638 & 7.892 & 12.18 & 74.61 & 3.82 \\
\hline DT seepage & & 14.01 & $1.052 e-08$ & 63.22 & 1.11 \\
\hline $\mathrm{BD}$ seepage & & 1.279 & 26.96 & 26.28 & 0.05 \\
\hline $\mathrm{XH}$ seepage & & 6.771 & 5.569 & 29.27 & 0.00097 \\
\hline
\end{tabular}

a special form of Hoek-Brown criterion is obtained by setting $A=0$ in the equation above. Equation (11) can be explicitly expressed as follows:

$$
\sigma_{1 \max }=\sigma_{3}+\sigma_{\mathrm{c}}-\sigma_{\mathrm{D}}+\sqrt{m \sigma_{\mathrm{c}} \sigma_{3}+\sigma_{\mathrm{D}}^{2}}
$$

2.2.5. Exponential Yield Criterion. By recognizing that the heterogeneity, cohesive force, and friction cannot coexist in a rock material, You $[14,31]$ postulates that with an increase of minimum principal stress, the maximum shear stress or the principal stress deviator in rock tends to approach a constant. Therefore, an exponential yield criterion with three unknown parameters is obtained as follows:

$$
\sigma_{1 \max }-\sigma_{3}=Q_{\infty}-\left(Q_{\infty}-Q_{0}\right) \exp \left[-\frac{\left(K_{0}-1\right) \sigma_{3}}{Q_{\infty}-Q_{0}}\right]
$$

where $Q_{0}$ denotes the uniaxial compressive strength, $Q_{\infty}$ denotes the yield differential principle stress, and $K_{0}$ denotes the impact factor on strength for a zero confining pressure.

2.3. Comparative Analysis on Yield Criteria. In this paper, the triaxial compressive test data under different coal conditions are used to compare and analyze the applicability of the following five yield criteria.

(1) Coulomb yield criterion, Equation (2)

(2) Parabolic Mohr criterion, Equations (6) and (7)

(3) Hoek-Brown yield criterion, Equations (9) and (10)

(4) Quadratic polynomial criterion, Equations (11) and (12)

(5) Exponential yield criterion, Equation (13)

\section{Comparative Analyses of Yield Criteria}

3.1. Metrics for Assessing the Regression Quality of Yield Criteria. The least square method is used to determine the unknown parameters in the formula, which can minimize the summation over the square of error between the model prediction and measurement data.

$$
\delta_{1}=\sum\left[\sigma_{\mathrm{s}}-f\left(\sigma_{3}\right)\right]^{2}
$$

You [13] conducts regression on the experimental data by using two different methods, i.e., minimizing the sum of square of error and minimizing the sum of absolute error. The study indicates that the latter approach can highlight the outliers in the measurement data and ensure that the measured points are distributed over both sides of the fitted curve in a balanced manner while staying as close as possible to the fitted curve.

$$
\delta_{2}=\sum \operatorname{abs}\left[\sigma_{\mathrm{s}}-f\left(\sigma_{3}\right)\right]
$$

For this reason, the present study is aimed at minimizing the sum of absolute error so as to determine the unknown parameters in the formula and uses $\delta_{2 \mathrm{~m}}$ to indicate the average fitting error:

$$
\delta_{2 \mathrm{~m}}=\frac{\sum \mathrm{abs}\left[\sigma_{\mathrm{s}}-f\left(\sigma_{3}\right)\right]}{N}=\frac{\delta_{2}}{N},
$$

where $N$ denotes the number of data points.

3.2. Comparative Analyses of Coal Strength Criteria. The present study applies curve fitting to the data of triaxial compression test on the coal rock samples as well as the triaxial compression test data published by Su et al. [32] and Yang et al. [33, 34] (as shown in Table 1), based on Coulomb criterion, parabolic Mohr criterion, Hoek-Brown criterion, quadratic polynomial criterion, and exponential strength criterion, respectively, with the fitted parameters shown in Tables 2 and 3, and the fitted curves associated with various yield criteria under the same coal rock condition shown in Figure 2. To facilitate the comparison, the fitting errors corresponding to the five yield criteria studied here are shown with a column diagram in Figure 3 . It can be seen that for the natural water-bearing coal samples, the linear Coulomb yield criterion exhibits a large fitting error, while the parabolic Mohr criterion yields a lower fitting error compared with the linear Coulomb yield criterion for all tested cases 


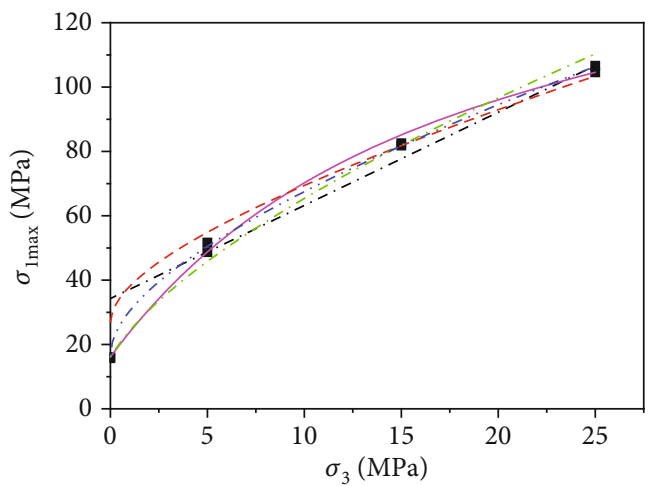

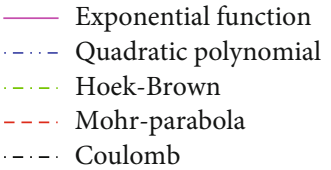

(a)

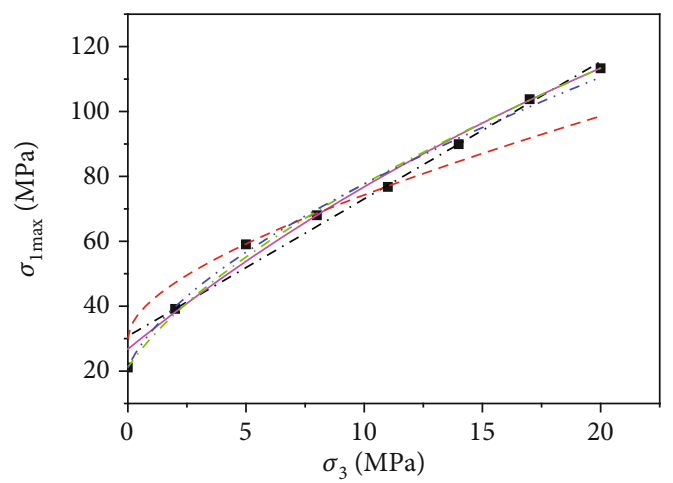

- Exponential function

-..- Quadratic polynomial

.... Hoek-Brown

- . Mohr-parabola

-. - Coulomb

(c)

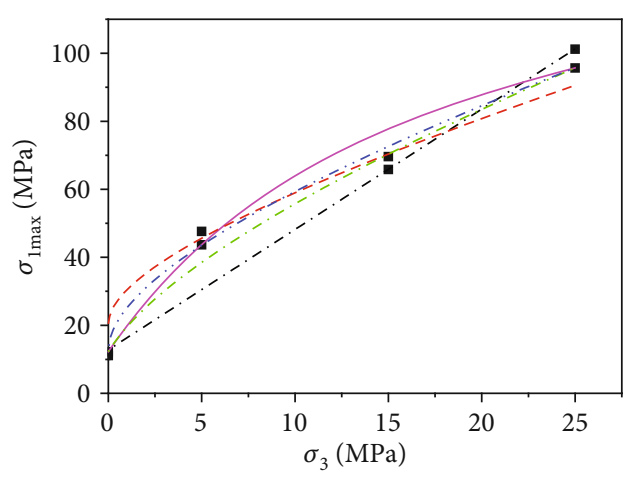

- Exponential function

-... Quadratic polynomial

.... Hoek-Brown

-... Mohr-parabola

..... Coulomb

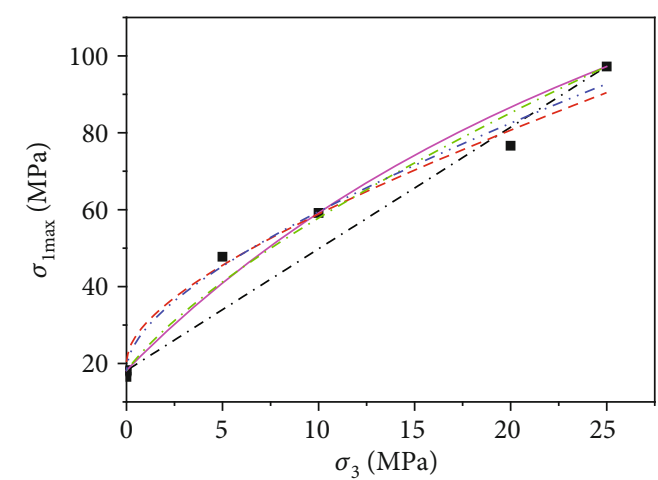

_ Exponential function

.... Quadratic polynomial

-... Hoek-Brown

- . - Mohr-parabola

.... Coulomb

(b)

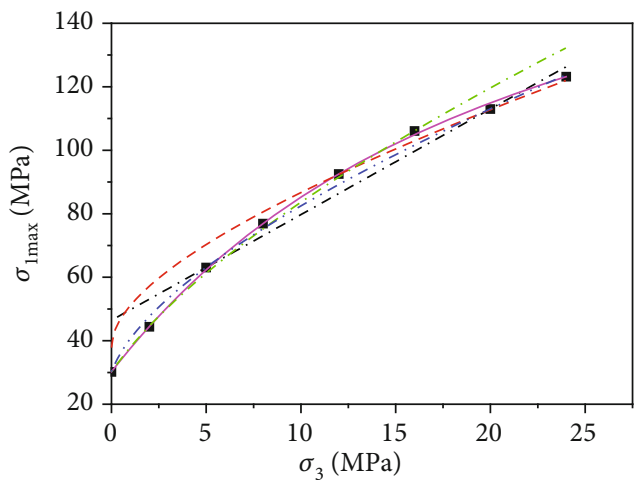

_- Exponential function

.... Quadratic polynomial

.... Hoek-Brown

_. - . Mohr-parabola

-... Coulomb

(d)

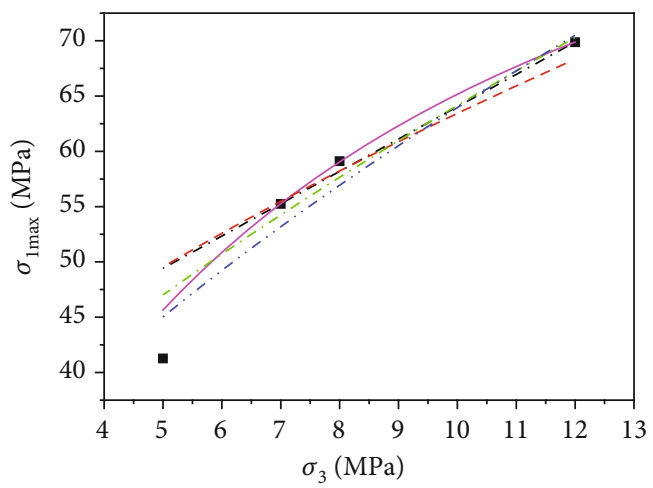

__ Exponential function

.... Quadratic polynomial

.... Hoek-Brown

... Mohr-parabola

.... Coulomb

(e)

(f)

Figure 2: Continued. 


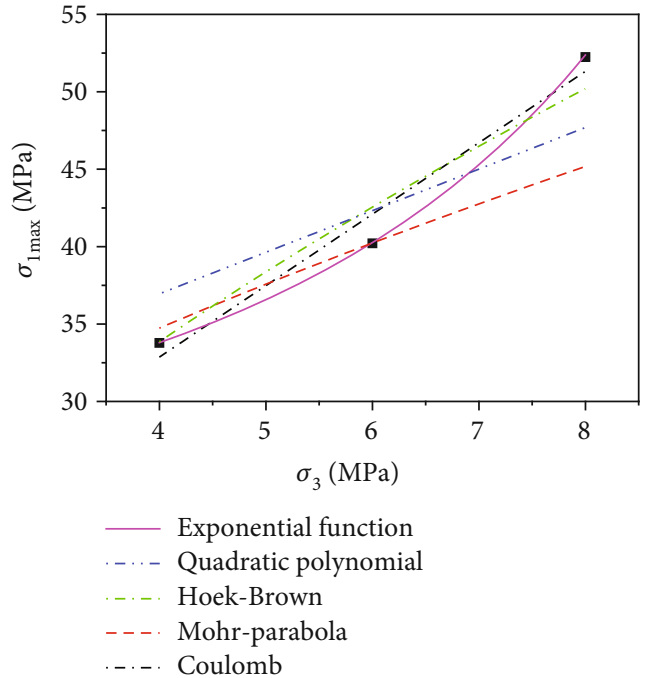

(g)

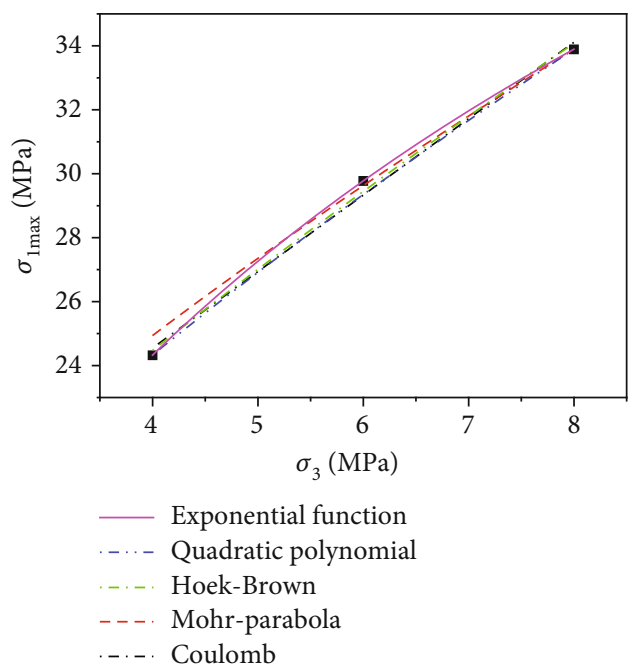

(h)

FIGURE 2: Triaxial compressive strength of coal samples and fitted curves of five yield criteria. (a) DT Natural coal. (b) BD Natural coal. (c) XH Natural coal. (d) YC Natural coal. (e) DT Water-saturated coal. (f) DT Seepage coal. (g) BD Seepage coal. (h) XH Seepage coal.

except the $\mathrm{XH}$ natural coal sample. However, the uniaxial compressive strength of a complete rock $\sigma_{c}$ obtained based on Equation (7) is significantly higher than that of the measured data. In other words, the calibrated parabolic Mohr criterion tends to overestimate the uniaxial compressive strength of the rock. For the Hoek-Brown criterion, quadratic polynomial criterion, and exponential strength criterion, the corresponding fitting errors are all less than those associated with the linear yield criterion and the parabolic Mohr criterion. Except that the quadratic polynomial criterion fails to decently fit the $\mathrm{BD}$ and $\mathrm{XH}$ natural coal samples, the fitted uniaxial strength of coal rock derived from the three criteria above all agree well with experimental data, and the performances of Hoek-Brown and exponential yield criteria are particularly satisfactory.

For water-saturated coal and compressive seepage coal, the linear yield criterion and the parabolic Mohr criterion still yield large errors in fitting the measured data. The cohesive force of the natural coal derived from the Coulomb criterion is smaller than those of all the other coal samples, e.g., water-saturated and seepage coal samples, except for the DT coal sample. The internal friction angle of the natural coal sample is smaller than those of all the water-saturated and seepage coal samples, except for the XH water-seeping coal with well-developed fractures and pore space [34], whose internal friction angle is smaller than that of the DT water-saturated coal and slightly larger than that of the DT natural coal. Due to the complex distribution of fine joints, fractures, and pore space in the coal, the linear yield criterion cannot authentically reflect the actual variation of coal strength, and thus, the applicability of the internal friction angle computed from the linear criterion to describing the mechanical characteristics of the rock needs further experimental validation.

In addition to the $\mathrm{BD}$ seepage coal test, the Hoek-Brown criterion, the quadratic polynomial criterion, and the expo- nential yield criterion can also decently fit the experimental strength data of the water-saturated and water-seeping rock samples, with the exponential yield criterion giving the best result, as shown in Figure 3. However, considering the mechanical interpretation underlying the exponential yield criterion, the DT seepage uniaxial compressive strength $Q_{0}$ derived from the exponential yield criterion shows a local minimum value, which is inconsistent with the reality. In addition, the fitting parameters of the exponential yield criterion, $Q_{0}$, all give low fitting errors, implying its ability to truly reflect the uniaxial strength of the coal rock. It is noteworthy that, for both the natural coal rock and the water-saturated water-seeping coal rock, the yield differential principle stress, $Q_{\infty}$, derived from the exponential yield criterion is lower than the measured value. Intuitively speaking, however, the exponential yield criterion exhibits a major advantage in fitting the strength data of the water-seeping coal. Therefore, it is necessary to conduct further experimental validation concerning the applicability of the exponential yield criterion to analyzing the coal rock strength.

\section{Comparative Analyses of Yield Criteria with the Presence of Pore Water in Coal}

In 1936, Terzaghi proposed the principle of effective stress [35]. According to the principle of effective stress, the total stress in the soil is equal to the sum of the effective stress and the pore water pressure, and only the change of effective stress will cause the change of strength. In the field of geotechnical engineering, the complex groundwater environment and the huge engineering risks associated with it have prompted engineering professionals to introduce the principle of effective stress into rock mechanics for rock strength analysis. To further analyze the effect of pore pressure on the mechanical properties of coal, the effective stress principle and the aforementioned test results are 


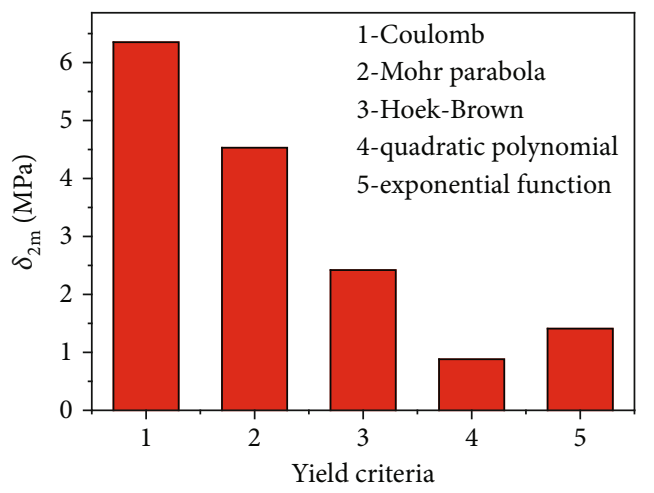

(a)

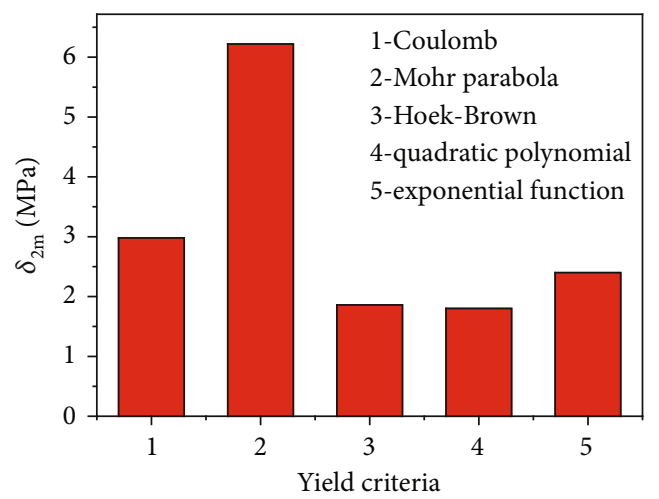

(c)

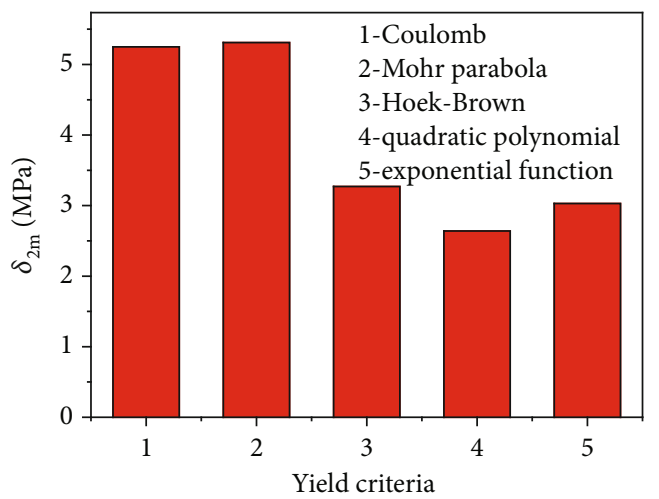

(e)

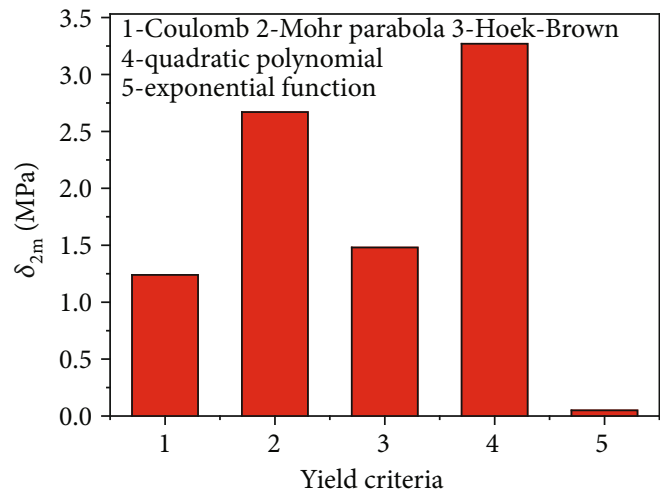

(g)

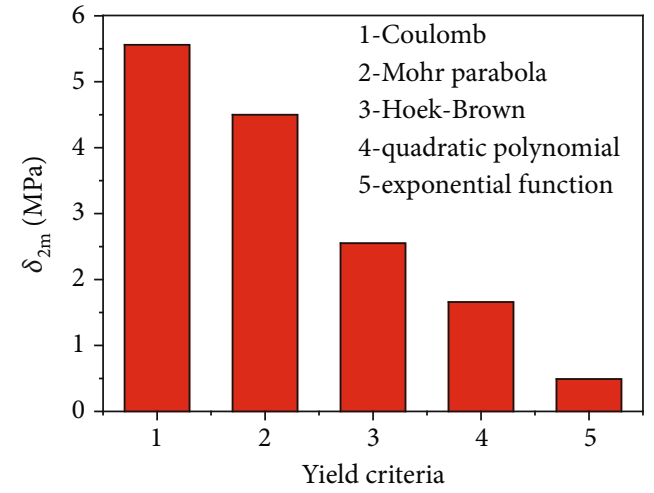

(b)

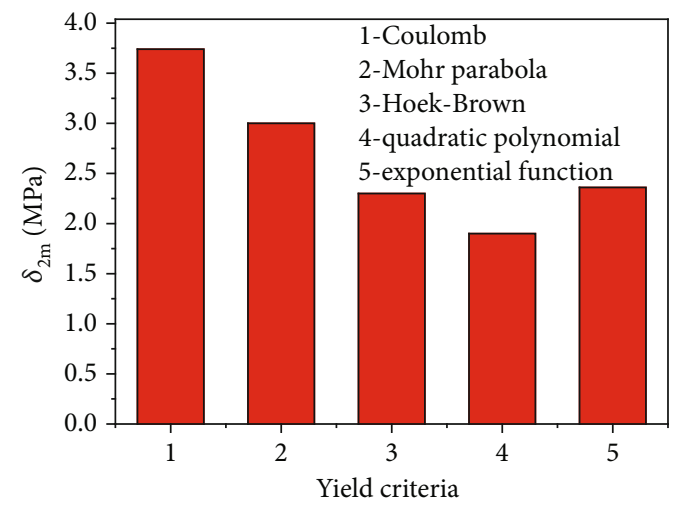

(d)

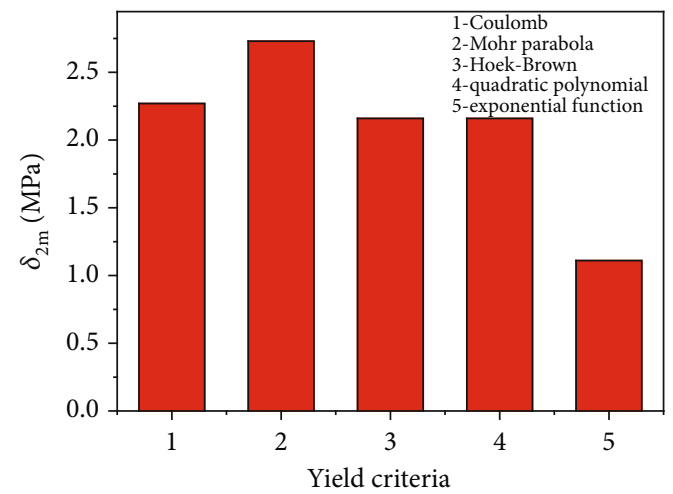

(f)

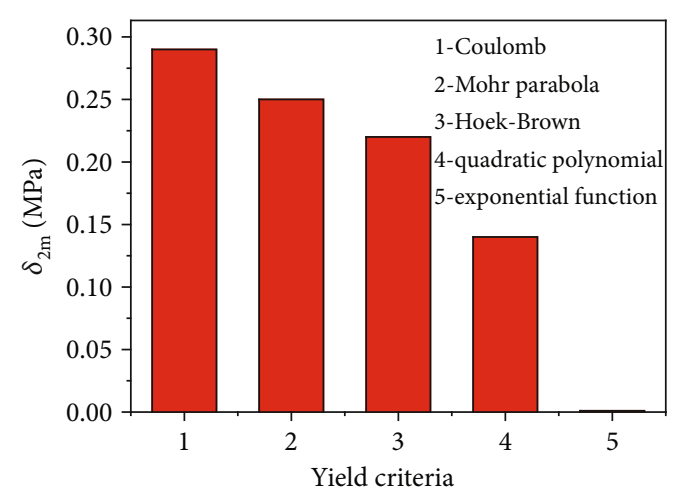

(h)

FIGURE 3: Mean fitting deviations of five yield criteria. (a) DT Natural coal. (b) BD Natural coal. (c) XH Natural coal. (d) YC Natural coal. (e) DT Water-saturated coal.(f) DT Seepage coal. (g) BD Seepage coal. (h) XH Seepage coal. 
TABLE 4: Triaxial strength fitting results of five effective yield criteria for saturated coal based on the least absolute deviation.

\begin{tabular}{lccccccccccc}
\hline \multirow{2}{*}{ Category } & $\zeta$ & \multicolumn{3}{c}{ Coulomb criterion } & \multicolumn{3}{c}{ Parabolic Mohr criterion } & \multicolumn{3}{c}{ Hoek-Brown criterion } \\
& & $c(\mathrm{MPa})$ & $\varphi\left(^{\circ}\right)$ & $\delta_{2 \mathrm{~m}}(\mathrm{MPa})$ & $\sigma_{\mathrm{c}}(\mathrm{MPa})$ & $\sigma_{\mathrm{D}}(\mathrm{MPa})$ & $\delta_{2 \mathrm{~m}}(\mathrm{MPa})$ & $m$ & $\sigma_{\mathrm{c}}(\mathrm{MPa})$ & $\delta_{2 \mathrm{~m}}(\mathrm{MPa})$ \\
& 0.01 & 3.403 & 34.99 & 5.47 & 21.53 & 0.0005366 & 5.59 & 16.89 & 12.18 & 3.44 \\
DT water-saturated & 0.05 & 3.522 & 39.58 & 6.68 & 23.83 & $2.09 e-05$ & 6.33 & 23.23 & 12.18 & 4.63 \\
& 0.08 & 4.458 & 42.97 & 8.23 & 27.13 & $1.573 e-07$ & 8.07 & 33.1 & 12.18 & 6.97 \\
\hline \multirow{2}{*}{ Category } & $\zeta$ & \multicolumn{4}{c}{ Quadratic polynomial criteria } & & \multicolumn{2}{c}{ Exponential yield criterion } \\
& 0.01 & 10.5 & 13.31 & $1.073 e-06$ & 2.94 & 0.01 & 8.758 & 12.18 & 73.85 & 3.99 \\
DT water-saturated & 0.05 & 8.424 & 18.34 & 0.0001455 & 4.66 & 0.05 & 16.17 & 12.18 & 71.28 & 5.08 \\
& 0.08 & 21.03 & 12.18 & $3.368 e-08$ & 5.73 & 0.08 & 59.29 & 12.18 & 55.24 & 6.91 \\
\hline
\end{tabular}

used to evaluate the applicability of the Coulomb criterion, the parabolic Mohr criterion, the Hoek-Brown criterion, the quadratic polynomial criterion, and the exponential yield criterion to computing the strength of water-saturated and water-seeping rock samples. Herein, the maximum axial stress $\sigma_{1 \max }$ and the confining pressure $\sigma_{3}$ corresponding to the coal rock solid skeleton under the pore pressure are expressed as the effective maximum axial stress $\sigma_{1 \max }^{\prime}$ and the effective confining pressure $\sigma_{3}^{\prime}$.

4.1. Comparative Analyses of Yield Criteria in WaterSaturated Nonseeping Coal. During triaxial compression tests on the water-saturated rock sample, the water present within the fractures and pore spaces between solid particles in the solid skeleton of the coal rock is subject to a combination of axial, confining, and pore pressure [36, 37]. Existing research has shown that under the physical processes of water lubrication, softening, argillization, drying and wetting, freezing and thawing, the chemical processes of dissolution, hydration, hydrolysis, acidification, and oxidation, and the mechanical effects of pore water pressure, the mechanical property parameters of rock, such as strength, all decrease in a groundwater environment [38-40]. Although the structure and composition of coal rock is different from other rocks, studies have shown that the strength limit of coal rock is also related to its degree of water saturation and pore pressure $[41,42]$. During the saturated nonseeping compression test, the pore pressure enclosed in the solid skeleton also increased in response to the compression of the solid skeleton, and the resulting pore pressure is related to the volumetric stress of the coal rock skeleton. Therefore, the pore pressure inside the coal rock should be $\zeta\left(\sigma_{1}+2 \sigma_{3}\right)$, where $\zeta$ denotes the coefficient related to the porosity and its distribution within the coal rock, with the value ranging between 0 and 1 . As a result, the effective strength associated with the saturated nonpermeating coal rocks can be calculated as follows:

$$
\left.\begin{array}{l}
\sigma_{1 \max }^{\prime}=\sigma_{1 \max }-\zeta\left(\sigma_{1 \max }+2 \sigma_{3}\right) \\
\sigma_{3}^{\prime}=\sigma_{3}-\zeta\left(\sigma_{1 \max }+2 \sigma_{3}\right)
\end{array}\right\} .
$$

Using the five yield criteria above, the experimental data tied to the effective strength of DT saturated coal under different conditions are fitted, and the average fitting errors are analyzed, as shown in Table 4. For the sake of conciseness, this paper only presents the fitted parameters and the corresponding fitting errors of the effective coal strength for $\zeta$ being $0.01,0.05$, and 0.08 . In order to intuitively illustrate the performance of each criterion in fitting the measurement data of saturated coal rock, the fitting errors of various yield criteria are shown in a column diagram (Figure 4), with Figure 5 showing the corresponding fitted curves of the five yield criteria for $\zeta=0.05$.

It can be seen that the Coulomb criterion and the parabolic Mohr criterion yield large fitting errors, and the parabolic Mohr criterion tends to overestimate the uniaxial compressive strength of saturated coal rock. In addition, it is found from the Coulomb criterion-based fitting data under different pore pressure conditions that the internal friction angle and cohesion of saturated coal increase with the pore pressure. By contrast, the Hoek-Brown criterion, the quadratic polynomial criterion, and the exponential yield criterion are superior to the Coulomb criterion and the parabolic Mohr criterion in terms of the fitting quality of effective saturated rock strength. For a variety of pore pressures, the fitting errors of the three methods are comparable. All three methods can decently fit the uniaxial strength data of saturated coal rock.

Among the three yield criteria with small fitting errors, the Hoek-Brown criterion is regarded as a special case of the second-degree polynomial rule [14] (with $A=0$ in Equation (11)). Figure 6 shows the fitted curves of quadratic polynomial criterion and exponential yield criterion under different pore pressures. It can be seen in the figure that the fitting parameter $m$, as a measure of the rock hardness, increases with the pore pressure, that is, the rock skeleton gets reinforced under the influence of the pore pressure. Besides, from the fitting quality of the exponential yield criterion, one can conclude that with an increase of pore pressure, the yield differential principal stress $Q_{\infty}$ of the saturated coal rock gradually decreases, i.e., the increase of pore pressure compromises the yield stress of 


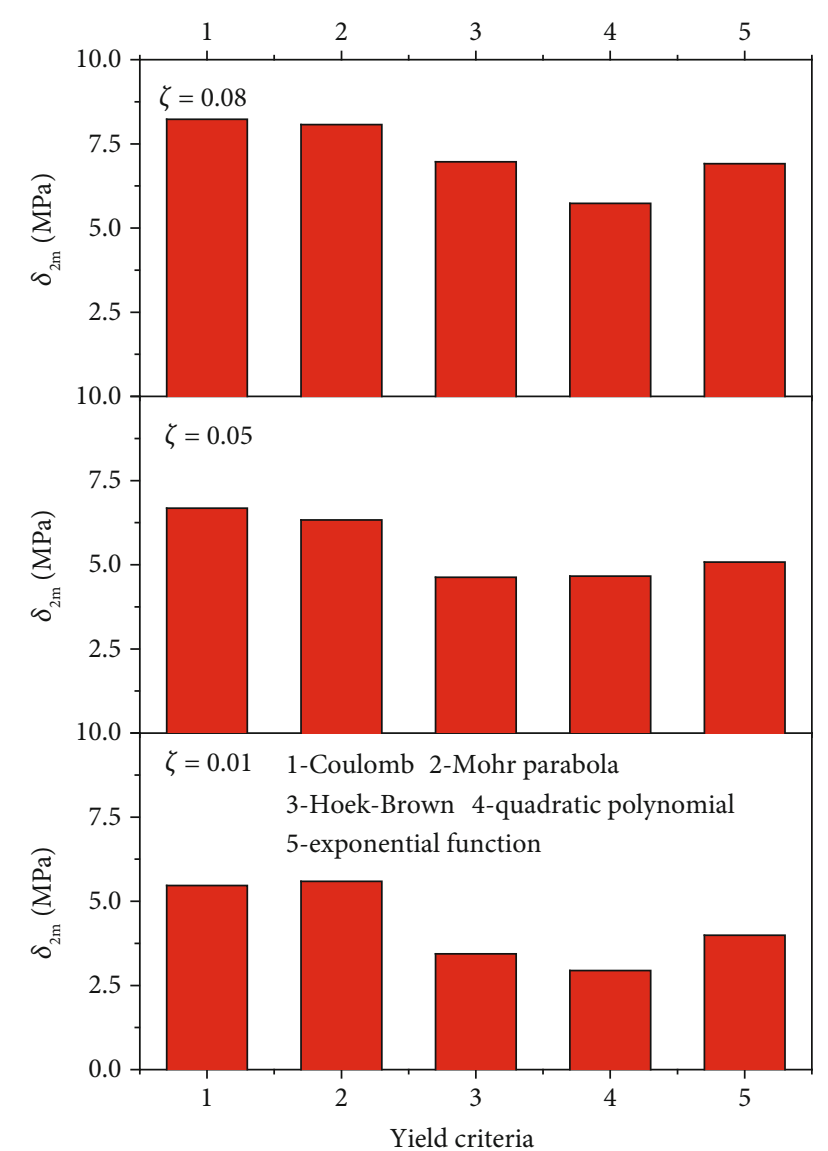

FIGURE 4: Mean fitting deviations of yield criteria for saturated DT coal samples.

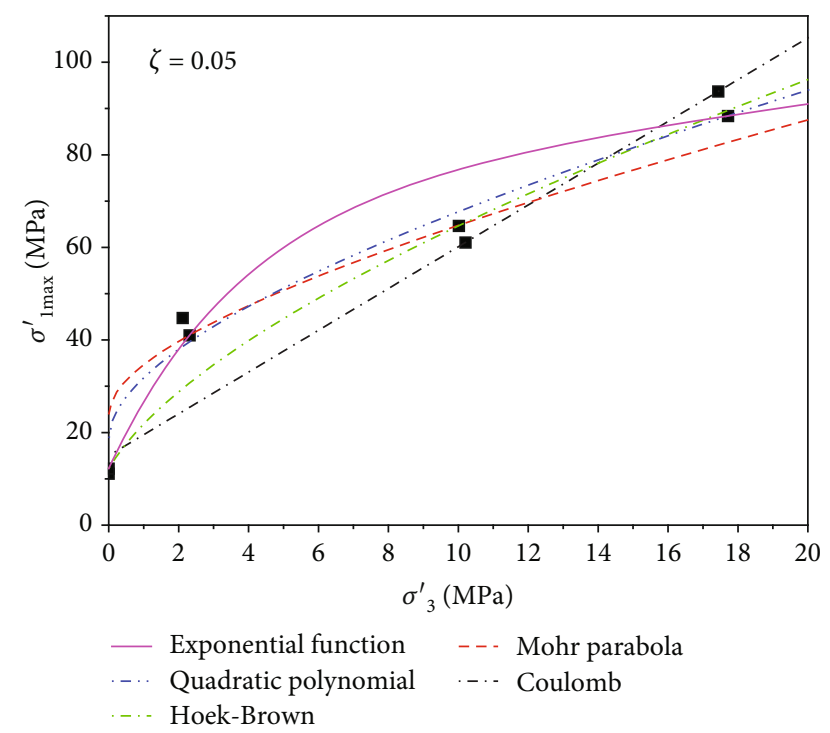

Figure 5: Triaxial compressive strength of water-saturated coal samples and fitted curves of five yield criteria.

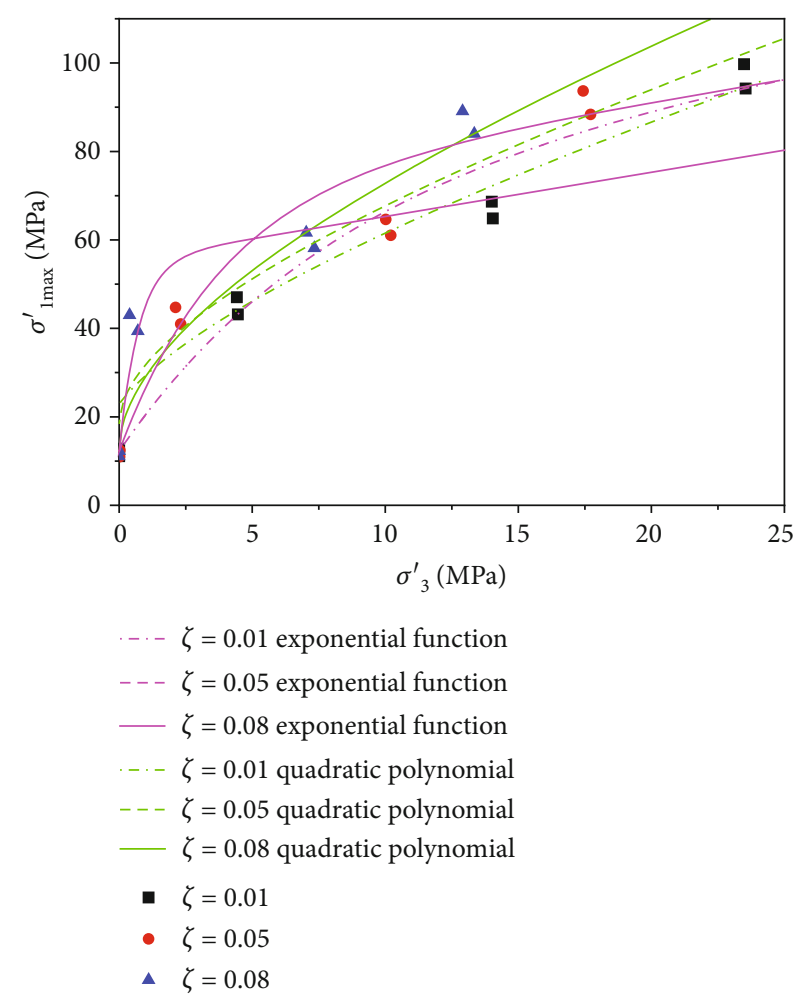

FIgURE 6: Triaxial compressive strength of water-saturated coal samples and the fitted curves of two yield criteria under different pore pressures.

coal rock. Nonetheless, the yield differential principal stress $Q_{\infty}$ fitted from the exponential yield criterion is still lower than the experimentally measured value. This deviation, however, is acceptable from the perspective of engineering construction safety.

4.2. Comparative Analyses of Yield Criteria in WaterSaturated Seeping Coal. The internal pores of coal samples are not always connected, so the internal pore water pressure is not necessarily equal to the water pressure exerted by the end face. Therefore, the pore water pressure in coal samples should be $\delta P$, where $\delta$ is the coefficient related to the porosity of coal and its connected state, and its value is related to the porosity of coal and its connected state. In addition, due to the existence of osmotic pressure differences in coal, pore water pressure is a function of pore distribution coordinate, but it is difficult to accurately determine its distribution state during the test. Therefore, two extreme assumptions were adopted to simplify estimation of the range of effective stress values on coal under conditions of saturated drainage.

(1) Assuming that the coal sample is absolutely dense, i.e., the porosity $\phi$ is 0 (completely impermeable), the water pressure applied to the specimen section is equivalent to the axial stress superimposed on the specimen section. Therefore, the effective stress on the coal is as follows: 
TABLE 5: Triaxial strength fitting results of five types of effective strength criteria for coal during a seepage process based on the least absolute.

\begin{tabular}{|c|c|c|c|c|c|c|c|c|c|c|}
\hline \multirow{2}{*}{ Category } & \multirow{2}{*}{$\phi$} & \multicolumn{3}{|c|}{ Coulomb criterion } & \multicolumn{3}{|c|}{ Parabolic Mohr criterion } & \multicolumn{3}{|c|}{ Hoek-Brown criterion } \\
\hline & & $c(\mathrm{MPa})$ & $\varphi\left(^{\circ}\right)$ & $\delta_{2 \mathrm{~m}}(\mathrm{MPa})$ & $\sigma_{\mathrm{c}}(\mathrm{MPa})$ & $\sigma_{\mathrm{D}}(\mathrm{MPa})$ & $\delta_{2 \mathrm{~m}}(\mathrm{MPa})$ & $m$ & $\sigma_{\mathrm{c}}(\mathrm{MPa})$ & $\delta_{2 \mathrm{~m}}(\mathrm{MPa})$ \\
\hline \multirow{2}{*}{ DT seepage } & 0 & 12.14 & 29.36 & 2.27 & 27.42 & $3.412 e-05$ & 1.69 & 5.085 & 40.16 & 2.09 \\
\hline & $\phi \pm$ & 11.29 & 29.36 & 2.28 & 24.72 & 0.001393 & 2.68 & 5.649 & 36.14 & 2.09 \\
\hline \multirow{2}{*}{ BD seepage } & 0 & 6.546 & 40.08 & 1.24 & 27.85 & 5.867 & 1.87 & 8.983 & 27.97 & 1.54 \\
\hline & $\phi \pm$ & 5.284 & 40.08 & 1.24 & 18.55 & $6.171 e-06$ & 2.01 & 12.48 & 20.14 & 1.54 \\
\hline \multirow{2}{*}{$\mathrm{XH}$ seepage } & 0 & 6.55 & 24.23 & 0.29 & 20.05 & 10.46 & 0.17 & 3.24 & 20.14 & 0.22 \\
\hline & $\phi \pm$ & 5.875 & 24.23 & 0.29 & 16.79 & 7.194 & 1.58 & 3.72 & 17.55 & 0.22 \\
\hline \multirow{2}{*}{ Category } & \multicolumn{5}{|c|}{ Quadratic polynomial criterion } & h & \multicolumn{4}{|c|}{ Exponential yield criterion } \\
\hline & $\psi$ & $m$ & $\sigma_{\mathrm{c}}(\mathrm{MPa})$ & $\sigma_{\mathrm{D}}(\mathrm{MPa})$ & $\delta_{2 \mathrm{~m}}(\mathrm{MPa})$ & $\psi$ & $K_{0}$ & $Q_{0}(\mathrm{MPa})$ & $Q_{\infty}(\mathrm{MPa})$ & $\delta_{2 \mathrm{~m}}(\mathrm{MPa})$ \\
\hline \multirow{2}{*}{ DT seepage } & 0 & 2.801 & 30.84 & 0.001214 & 1.65 & 0 & 14.28 & 20.68 & 60.05 & 0.17 \\
\hline & $\phi \pm$ & 4.342 & 24.96 & $4.045 e-05$ & 1.85 & $\phi \pm$ & 19.71 & $2.559 e-09$ & 60.64 & 0.23 \\
\hline \multirow{2}{*}{ BD seepage } & 0 & $1.026 e+04$ & 29 & $4.099 e+04$ & 0.94 & 0 & 4.617 & 28.12 & $1.377 e+04$ & 1.25 \\
\hline & $\phi \pm$ & $1.316 e+04$ & 22.93 & $4.133 e+04$ & 1.13 & $\phi \pm$ & 1.715 & 28.03 & 26.28 & 0.0054 \\
\hline \multirow{2}{*}{ XH seepage } & 0 & 0.7782 & 19.68 & 2.075 & 0.00065 & 0 & 3.288 & 19.87 & 29.27 & 0.0026 \\
\hline & $\phi \pm$ & 1.94 & 13.62 & $1.056 e-13$ & 0.089 & $\phi \pm$ & 4.296 & 15.73 & 29.27 & 0.0012 \\
\hline
\end{tabular}
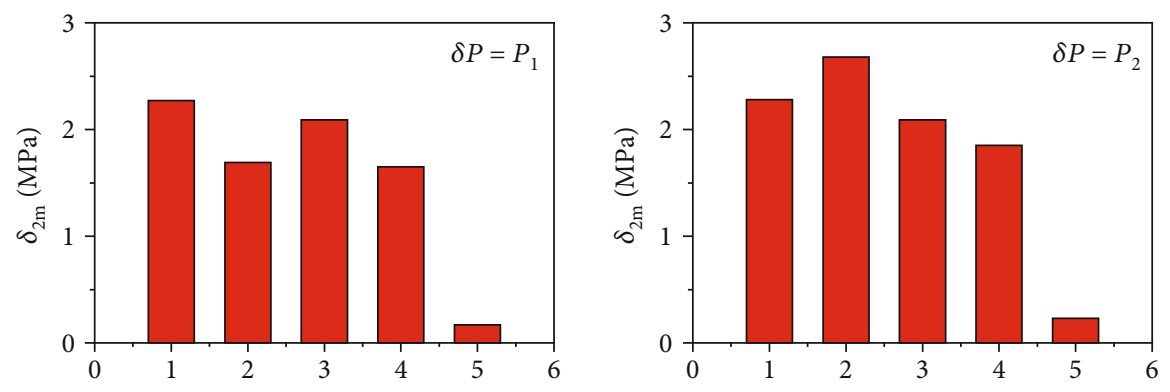

DT seepage coal
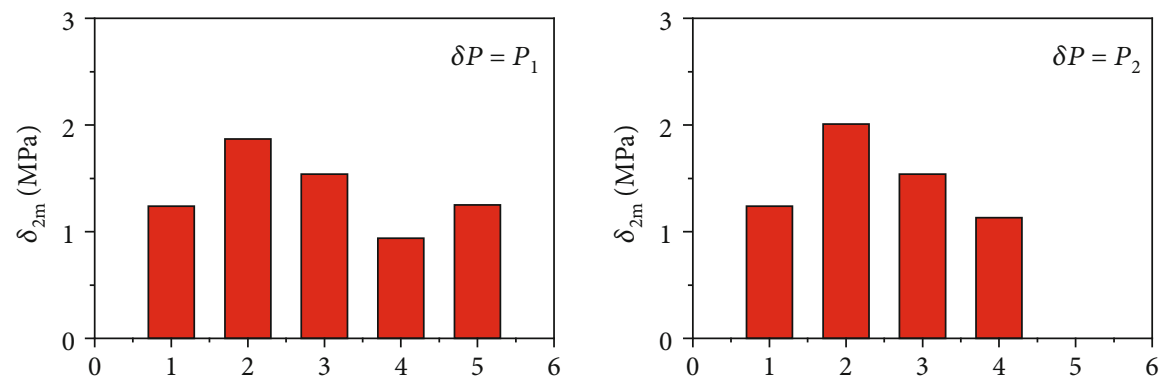

BD seepage coal

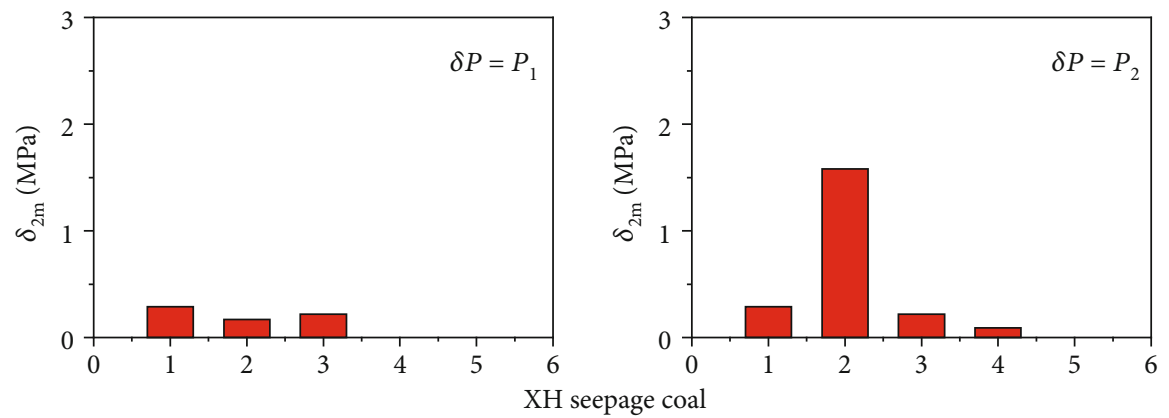

Figure 7: Mean fitting deviations of strength criteria for seepage coal samples. 


$$
\left.\begin{array}{l}
\sigma_{1 \max }^{\prime}=\sigma_{1 \max }+P \\
\sigma_{3}^{\prime}=\sigma_{3}
\end{array}\right\} .
$$

(2) Assuming that the porosity of the coal sample is large enough to make its structure similar to that of soil, the effective stress on the coal is as follows:

$$
\left.\begin{array}{l}
\sigma_{1 \max }^{\prime}=\sigma_{1 \max } \\
\sigma_{3}^{\prime}=\sigma_{3}-P
\end{array}\right\} .
$$

Due to the complex structure of pores and fractures in coal, it is impossible to specifically calculate the effective stress on the internal skeleton of coal. However, from formula (18) and formula (19), it can be seen that the effective stress on seepage coal is somewhere between the two. Therefore, based on the above two extreme hypotheses, the maximum value of effective stress is selected for analysis by fitting data of the effective strength of seepage coal. Table 5 shows the fitting parameters and average fitting deviation of different strength criteria of seepage coal.

It can be seen from Figure 7 that the Hoek-Brown criterion, quadratic polynomial criterion, and exponential yield criterion are better than the Coulomb criterion and parabolic Mohr criterion, and especially the exponential yield criterion. Figure 8 shows the fitting curve of the DT seepage coal quadratic polynomial criterion and the exponential yield criterion, from which we can see that the exponential yield criterion has a good fitting deviation for the effective strength of seepage coal. However, due to the limited amount of coal seepage test data, the exponential yield criterion for the partial seepage test coal data, the fitting parameters of uniaxial compression strength $Q_{0}$, and the ultimate principal stress difference $Q_{\infty}$ are not accurate. Therefore, to apply the exponential yield criterion to the effective strength of seepage coal, further seepage tests are needed.

\section{Conclusion}

(1) With an increase of confining pressure, the coal rock strength shows a nonlinear characteristic. The linear Coulomb yield criterion cannot describe this behavior well, showing a large fitting error. It is therefore necessary to conduct experimental validation when it comes to using its internal friction angle and cohesion to describe the variation of the rock's mechanical properties

(2) Although the parabolic Mohr yield criterion can reflect to certain extent the nonlinear characteristics of coal rock strength, its fitting error is too large, and the fitted parameters are inconsistent with the reality

(3) The Hoek-Brown criterion, quadratic polynomial criterion, and exponential yield criterion all exhibit decent fitting quality, i.e., they can all reflect the characteristics of coal strength under natural and fluid-structure interactions. The exponential yield criterion, in particular, can truly reflect the uniaxial com-

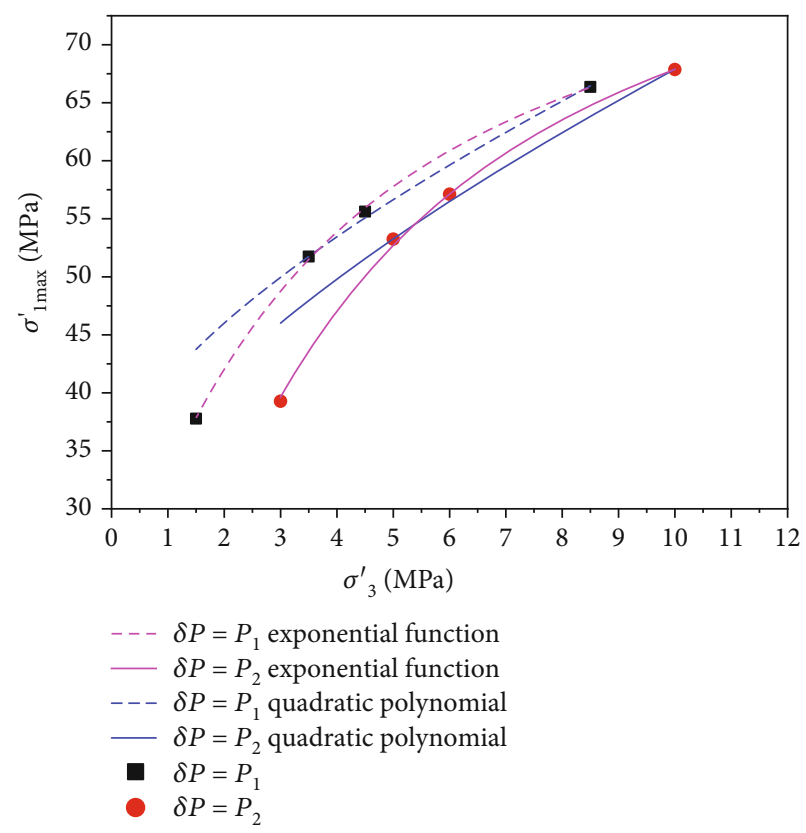

Figure 8: Triaxial compression strengths of DT coal samples and fitting curves of two strength criteria under seepage pressures.

pressive strength of coal. Although the yield strength of the rock derived from the exponential yield criterion is less than the measured value, such conservative approach is favored for ensuring engineering safety

Although the test and analysis results presented in this paper provide some insights into the applicability of various yield criteria to characterize the yield variation (especially with the presence of fluid-solid interaction), the size and self-consistency of experimental dataset is limited; thereby, the conclusions presented in this paper are preliminary. As such, the applicability of various yield criteria still requires further experimental analyses.

\section{Data Availability}

The data used to support the findings of this study have not been made available.

\section{Conflicts of Interest}

The authors declare that they have no conflicts of interest.

\section{Acknowledgments}

This work was supported by the Key National Natural Science Foundation of China (Grant No. 51934004), the National Natural Science Foundation of China (Grant Nos. 51704184, 51904171), the Shandong Natural Science Foundation of China (Grant Nos. ZR2018ZA0602, ZR2019BG007), the China Postdoctoral Science Foundation (Grant No. 2018M642681), the Opening Foundation of State Key Laboratory of Mining Disaster Prevention and Control cofounded by Shandong Province and the Ministry of 
Science and Technology (Grant No. MDPC201815), the Opening Foundation of Shandong Key Laboratory of Civil Engineering Disaster Prevention and Mitigation (Grant No. CDPM2019ZR09), and the 2019 Graduate Science and Technology Innovation Funded Project (Grant No. SDKDYC190233).

\section{References}

[1] X. Liu, Y. Zhuang, L. Liang, and J. Xiong, "Investigation on the influence of water-shale interaction on stress sensitivity of organic-rich shale," Geofluids, vol. 2019, Article ID 2598727, 13 pages, 2019.

[2] B. Sun, W. Cheng, J. Wang, H. Wang, and Y. Ma, "Development of Venturi negative-pressure secondary dedust device and application of local spray closure technique," Powder Technology, vol. 30, no. 1, pp. 42-54, 2019.

[3] B. H. G. Brady and E. T. Brown, Rock Mechanics for Underground Mining, Springer, Netherlands, 2006.

[4] W. Y. Zhou, Advanced Rock Mechanics, Water Conservancy and Electric Power Press, Beijing, 1990.

[5] M. F. Cai, Rock Mechanics and Engineering, Science Press, Beijing, 2002.

[6] E. Hoek and E. T. Brown, "Practical estimates of rock mass strength," International Journal of Rock Mechanics and Mining Sciences, vol. 34, no. 8, pp. 1165-1186, 1997.

[7] L. R. Alejano and A. Bobet, "Drucker-Prager criterion," Rock Mechanics and Rock Engineering, vol. 45, no. 6, pp. 995-999, 2012.

[8] M. Q. You, Rock Mechanical Properties, Geological Press, Beijing, 2007.

[9] K. Mogi, "Fracture and flow of rocks under high triaxial compression," Journal of Geophysical Research, vol. 76, no. 5, pp. 1255-1269, 1971.

[10] S. A. F. Murrell, "The effect of triaxial stress systems on the strength of rocks at atmospheric temperatures," Geophysical Journal International, vol. 10, no. 3, pp. 231-281, 1965.

[11] Z. T. Bieniawski, "Estimating the strength of rock materials," Journal of the Southern African Institute of Mining and Metallurgy, vol. 74, no. 8, pp. 312-320, 1974.

[12] B. S. Liu, Z. L. Cui, and J. F. Tu, "A study of strength criterion in power function for rock material," Chinese Journal of Rock Mechanics and Engineering, vol. 16, no. 5, pp. 437-444, 1997.

[13] M. You, "Mechanical characteristics of the exponential strength criterion under conventional triaxial stresses," International Journal of Rock Mechanics and Mining Sciences, vol. 47, no. 2, pp. 195-204, 2010.

[14] M. Q. You, "Study of mathematical equation and parameter determination of yield criteria for rock," Chinese Journal of Rock Mechanics and Engineering, vol. 29, no. 11, pp. 21722184, 2010.

[15] Y. W. Zan, M. H. Yu, and S. J. Wang, "Nonlinear unified strength criterion of rock," Chinese Journal of Rock Mechanics and Engineering, vol. 21, no. 10, pp. 1435-1441, 2002.

[16] J. Zhao, "Applicability of Mohr-Coulomb and Hoek-Brown strength criteria to the dynamic strength of brittle rock," International Journal of Rock Mechanics and Mining Sciences, vol. 37, no. 7, pp. 1115-1121, 2000.

[17] A. M. Al-Ajmi and R. W. Zimmerman, "Relation between the Mogi and the Coulomb failure criteria," International Journal of Rock Mechanics and Mining Sciences, vol. 42, no. 3, pp. 431-439, 2005.

[18] A. M. Al-Ajmi and R. W. Zimmerman, "Stability analysis of vertical boreholes using the Mogi-Coulomb failure criterion," International Journal of Rock Mechanics and Mining Sciences, vol. 43, no. 8, pp. 1200-1211, 2006.

[19] R. Costamagna and O. T. Bruhns, "A four-parameter criterion for failure of geomaterials," Engineering Structures, vol. 29, no. 3, pp. 461-468, 2007.

[20] M. Q. You, "Normal parabolic criterion with a single parameter," Chinese Journal of Rock Mechanics and Engineering, vol. 31, no. 8, pp. 1580-1586, 2012.

[21] M. Q. You, "Strength and yield criteria for intact rocks," Journal of Fudan University (Natural Science), vol. 52, no. 5, pp. 569-582, 2013.

[22] O. Ojo and N. Brook, "The effect of moisture on some mechanical properties of rock," Mining Science and Technology, vol. 10, no. 2, pp. 145-156, 1990.

[23] B. Vásárhelyi, "Statistical analysis of the influence of water content on the strength of the Miocene limestone," Rock Mechanics and Rock Engineering, vol. 38, no. 1, pp. 69-76, 2005.

[24] B. Vásárhelyi and P. Ván, "Influence of water content on the strength of rock," Engineering Geology, vol. 84, no. 1-2, pp. 70-74, 2006.

[25] P. Baud, W. Zhu, and T.-f. Wong, "Failure mode and weakening effect of water on sandstone," Journal of Geophysical Research: Solid Earth, vol. 105, no. B7, pp. 16371-16389, 2000.

[26] R. Peng, Y. Ju, J. G. Wang, H. Xie, F. Gao, and L. Mao, "Energy dissipation and release during coal failure under conventional triaxial compression," Rock Mechanics and Rock Engineering, vol. 48, no. 2, pp. 509-526, 2015.

[27] T. P. Medhurst and E. T. Brown, "A study of the mechanical behaviour of coal for pillar design," International Journal of Rock Mechanics and Mining Sciences, vol. 35, no. 8, pp. 1087-1105, 1998.

[28] F. G. Bell and C. A. Jermy, "A laboratory investigation of some factors affecting the stability of a mine in the Eastern Transvaal coalfield South Africa," Environmental and Engineering Geoscience, vol. 8, no. 2, pp. 85-104, 2002.

[29] S. Kahraman and M. Alber, "Triaxial strength of a fault breccia of weak rocks in a strong matrix," Bulletin of Engineering Geology and the Environment, vol. 67, no. 3, pp. 435-441, 2008.

[30] G. Wang, W. Li, P. Wang, X. Yang, and S. Zhang, "Deformation and gas flow characteristics of coal-like materials under triaxial stress conditions," International Journal of Rock Mechanics and Mining Sciences, vol. 91, pp. 72-80, 2017.

[31] M. Q. You, "Characteristics of exponential strength criterion of rock in principal stress space," Chinese Journal of Rock Mechanics and Engineering, vol. 28, no. 8, pp. 1541-1551, 2009.

[32] C. Su, X. Zhai, Y. Li, S. Li, and Z. Liu, "Study on deformation and strength of coal samples in triaxial compression," Chinese Journal of Rock Mechanics and Engineering, vol. 25, no. z1, pp. 2963-2968, 2006.

[33] Y. J. Yang, Y. Song, and S. J. Chen, "Test study of coal's strength and deformation characteristics under triaxial compression," Journal of China Coal Society, vol. 2531, no. 2, pp. 150-153, 2006. 
[34] Y. J. Yang, Y. Song, and S. J. Chen, "Test study on permeability properties of coal specimen in complete stress-strain process," Rock Soil Mechanics, vol. 28, no. 2, pp. 381-385, 2007.

[35] Y. Li and D. Jia, "Fracture initiation model of shale fracturing based on effective stress theory of porous media," Geofluids, vol. 2018, Article ID 2053159, 12 pages, 2018.

[36] W. Cheng, Z. Liu, H. Yang, and W. Wang, "Non-linear seepage characteristics and influential factors of water injection in gassy seams," Experimental Thermal and Fluid Science, vol. 91, pp. 41-53, 2018.

[37] W.-m. Cheng, W. Nie, G. Zhou, Y. Yu, Y. Ma, and J. Xue, "Research and practice on fluctuation water injection technology at low permeability coal seam," Safety Science, vol. 50, no. 4, pp. 851-856, 2012.

[38] Z. D. Zhu, Y. Zhang, W. Y. Xu, F. D. Xing, and S. J. Wang, "Experimental studies and microcosmic mechanics analysis on marble rupture under high confining pressure and high hydraulic pressure," Chinese Journal of Rock Mechanics and Engineering, vol. 24, no. 1, pp. 44-51, 2005.

[39] J. Xu, H. W. Yang, S. J. Peng, Y. D. Jiang, and Y. Zhang, "Experimental study of mechanical property of sandstone under pore water pressure and confining pressure," Chinese Journal of Rock Mechanics and Engineering, vol. 29, no. 8, pp. 1618-1623, 2010.

[40] R. Q. Huang, Z. M. Xu, and M. Xu, "Hazardous effects of underground water and extraordinary water flow-induced geohazards," Earth and Environment, vol. 33, no. 3, pp. 1-9, 2005.

[41] Y. B. Yu, G. Zhou, L. J. Chen, B. Zhou, and X. H. Tian, “Experimental study on the basic mechanical properties of watersaturated coal rock," Mining Safety and Environmental Protection, vol. 41, no. 1, pp. 4-7, 2014.

[42] W. M. Cheng, Y. B. Yu, C. X. Wan, G. Zhou, and L. Zhang, "Study on seepage properties of coal under the role of high pore water pressure," Disaster Advances, vol. 7, no. 6, pp. 350-357, 2013. 